\title{
Impact of Environmental and Stress Factors on the Photosynthetic Capabilities of Plants
}

\author{
Jannatul Ferdous ${ }^{1}$, Md Mamun ${ }^{2}$, Md. Sarafat Ali ${ }^{3, *}$ \\ ${ }^{1}$ Department of Ecology and Population Genetics, University of Oulu, Finland \\ ${ }^{2}$ Department of Biological Science, Chungnam National University, South Korea \\ ${ }^{3}$ Department of Biotechnology and Genetic Engineering, Bangabandhu Sheikh Mujibur Rahman Science \& Technology University, \\ Bangladesh
}

Copyright $\mathrm{O} 2017$ by authors, all rights reserved. Authors agree that this article remains permanently open access under the terms of the Creative Commons Attribution License 4.0 International License

\begin{abstract}
Photosynthesis is the most fundamental and intricate physiological process in all green plants. For the fruitful occurrence of photosynthesis, each plant has certain environmental requirements. They are impacted by the environmental factors and stress during all phases of growth and development. Examples include light availability, water (soil moisture), senescence, carbon strategy and nutrient deficiencies etc. that cause alteration of the net photosynthesis rate of plants. In this study, to determine the effect of different environmental factors on photosynthesis, a number of experiments were conducted where the net photosynthesis, transpirations, water use efficiency and photoinhibition were measured. To study the effect of light intensity, soil moisture, senescence, on net photosynthesis, respectively Ocimum basilicum, Vaccinium vitis-idaea, Cotinus coggygria, were used. To compare carbon strategy, Pisum sativum and Zea mays were grown under similar condition. How variable nutrient conditions can affect the photosynthesis was studied using a light adapted plant Epilobium augustifolium and shaded tolerant plant Glechoma hederacea. Observations resulted that light intensity at mid-range increases the rate of photosynthesis but exceeding a certain amount caused lowering the efficiency. Net photosynthesis was the maximum under moist condition for Vaccinium vitis- idaea. On the other hand, the senescent leaf had highly similar transpiration rates as the healthy green leaf. Net photosynthesis rate of $\mathrm{C} 4$ plants were higher than $\mathrm{C} 3$ plants. Overall, the impact of environmental factors on the photosynthesis rate of different plant species was quite apparent.
\end{abstract}

Keywords Plant, Net Photosynthesis, Environmental Factors, Stress, Productivity

\section{Introduction}

Photosynthesis is the process by which light energy is used to synthesize reduced carbon compounds in green plants. Most photosynthesis occurs in foliage leaves [1]. For optimal photosynthesis, an ample supply of water, light and nutrients are required [2]. Light energy is harvested by pigment molecules and transferred to reaction centers where photochemical reactions occur that drive electron flow through a series of carriers [1]. The end result of this process is an increase in plants' growth and development.

The quality and quantity of solar radiation plays a vital role for growth and competition among plant species. Photosynthetically active radiation (PAR) is the range of wavelengths that plants absorb for energy, in the window of 400-700 nm [3]. The intensity of this radiation can have varying effects on plants and their ability to photosynthesize. Low light intensities can be stressful for plants because low energy input limits photosynthesis. High light intensities are also stressful for plants and cause damage to the photosynthetic mechanisms via photoinhibition [2]. Other factors that affect plants can have positive or negative impacts on the plants' ability to photosynthesize.

The focus of this study was to demonstrate how several environmental and stress factors affected the photosynthetic capabilities of different plants. Multiple plant species were used to study light intensity, soil moisture, temperature, senescence, carbon strategy and light and nutrient balance, and how variation in these factors affected the plants' net photosynthesis, transpiration, water use efficiency and response to photoinhibition.

\section{Materials and Methods}

\subsection{Plant Materials and Treatments}

Ocimum basilicum was used to determine the effect of light intensity on net photosynthesis. To study the effect of environmental and stress factors on plants several experiments were conducted where net photosynthesis, transpiration, water use efficiency and photoinhibition were 
measured for plants in each treatment. Vaccinium vitis-idaea was used to study the effect of soil moisture (moist and dry treatments) and temperature (cold). To study senescence in healthy green leaves and senescence in yellow leaves on the same Cotinus coggygria individual were selected for measurement (Table 1). Pisum sativum (C3) and Zea mays (C4) were grown under the same conditions to compare carbon strategy. A light adapted plant, Epilobium angustifolium, and a shade tolerant plant, Glechoma hederacea, were grown in variable light and nutrient conditions. Light conditions were either full light or shade. Shading was done with a mesh net, so plants only received $50 \%$ full light intensity. Nutrient levels were either irrigated with fertilized water or tap water without added fertilizers.

Table 1. Plant species used in photosynthesis experiments.

\begin{tabular}{|c|c|c|c|c|c|}
\hline Factor & $\begin{array}{c}\text { Light } \\
\text { Intensity }\end{array}$ & $\begin{array}{c}\text { Moisture/ } \\
\text { temperature }\end{array}$ & Senescence & Carbon strategy \\
\hline Species & $\begin{array}{c}\text { Ocimum } \\
\text { basilicum }\end{array}$ & $\begin{array}{c}\text { Vaccinium } \\
\text { vitis-idaea }\end{array}$ & Cotinus coggygria & $\begin{array}{c}\text { C3:Pisum sativum } \\
\text { C4: Zea mays }\end{array}$ \\
\hline
\end{tabular}

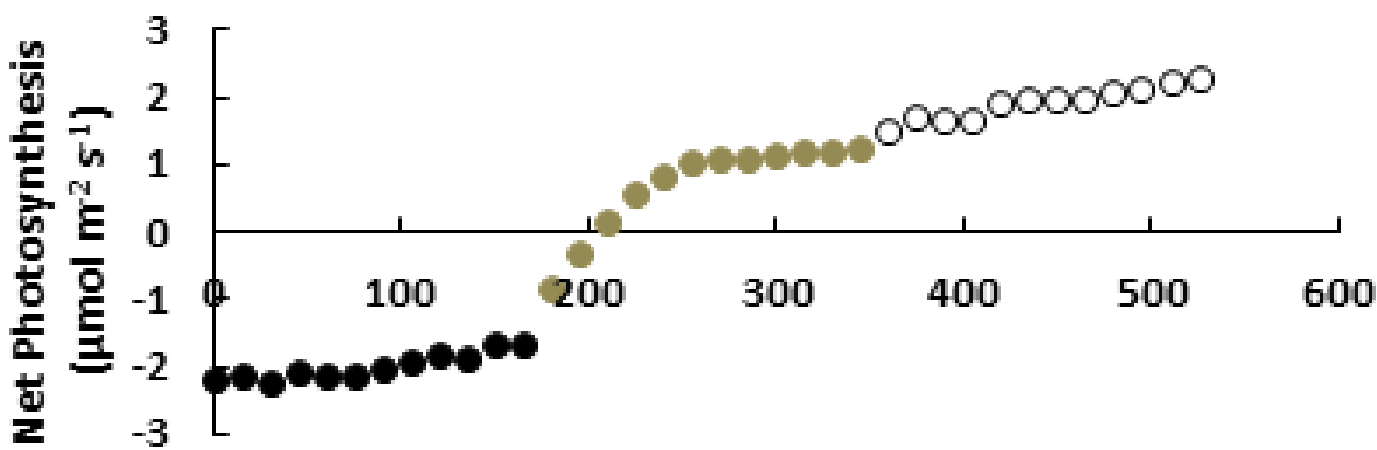

Time (s)

Figure 1. Effect of increasing PAR over time on photosynthesis in $O$. basilicum. Black circles: $\mathrm{PAR}=20$; grey circles: $\mathrm{PAR}=324$; white circles: $\mathrm{PAR}=$ 1024.

a.

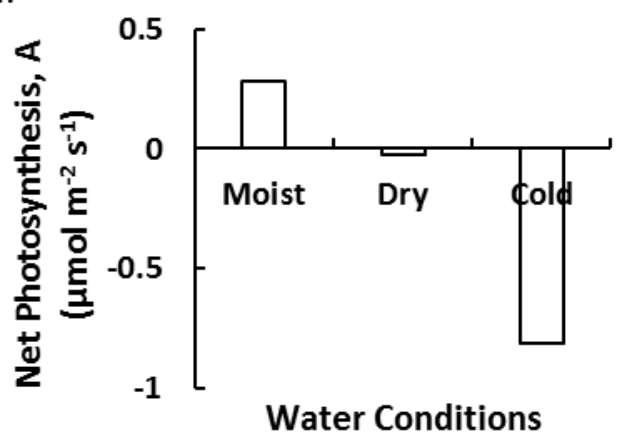

c.

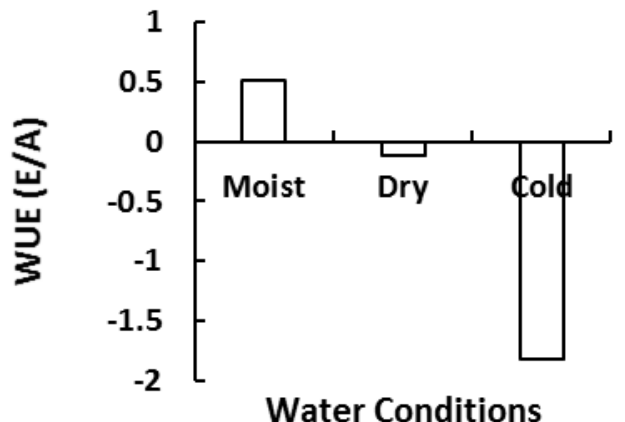

b.

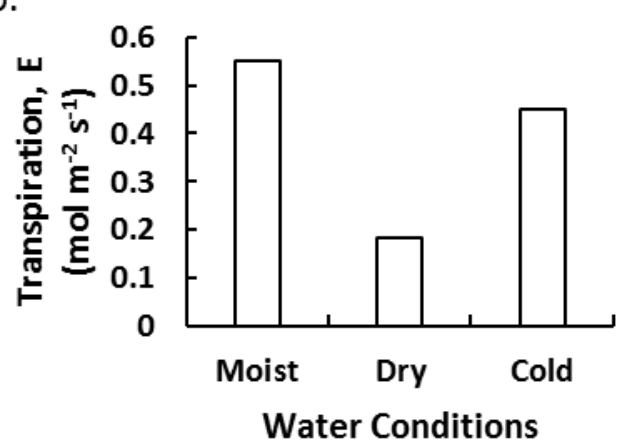

d.

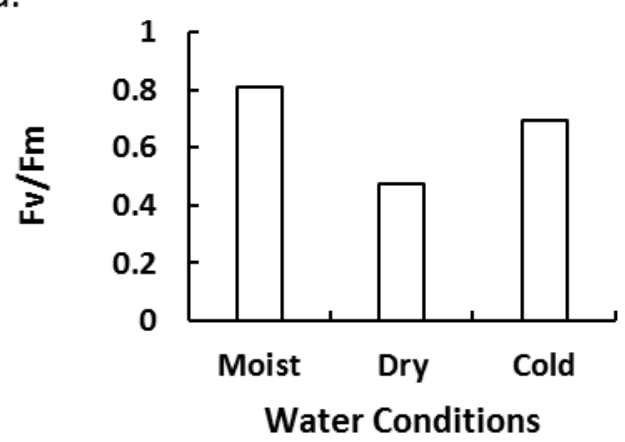

Figure 2. Effect of drought and cold on photosynthesis (a), transpiration (b), water use efficiency (WUE) (c), and photoinhibition (Fv/Fm) (d). 
a.

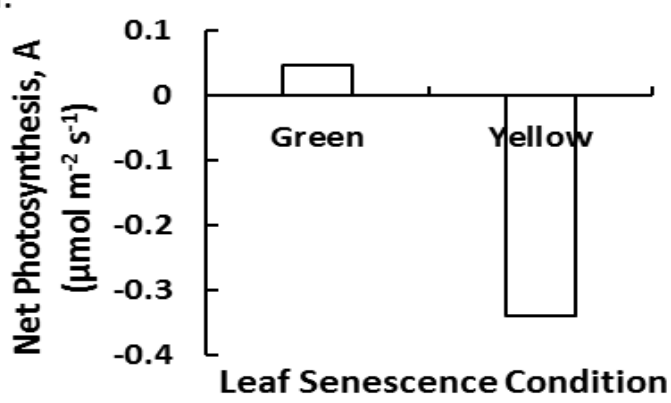

c.

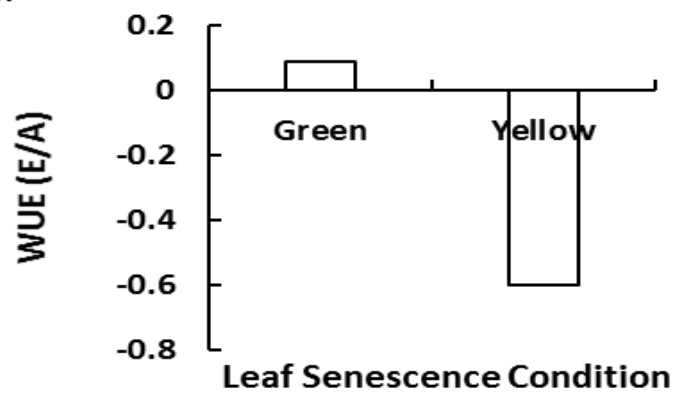

b.

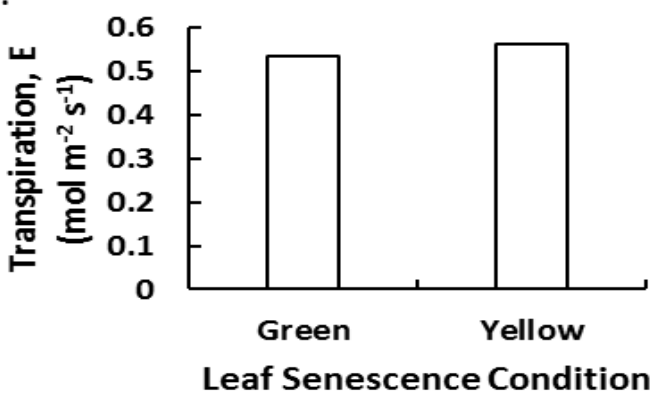

d.

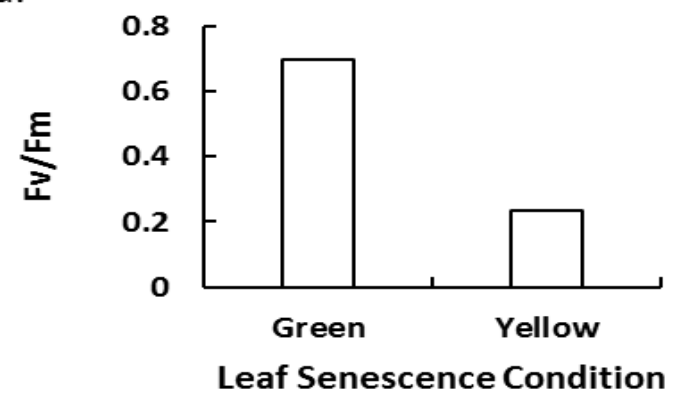

Figure 3. Effect of senescence on photosynthesis (a), transpiration (b), water use efficiency (WUE) (c), and photoinhibition (Fv/Fm) (d).

a.

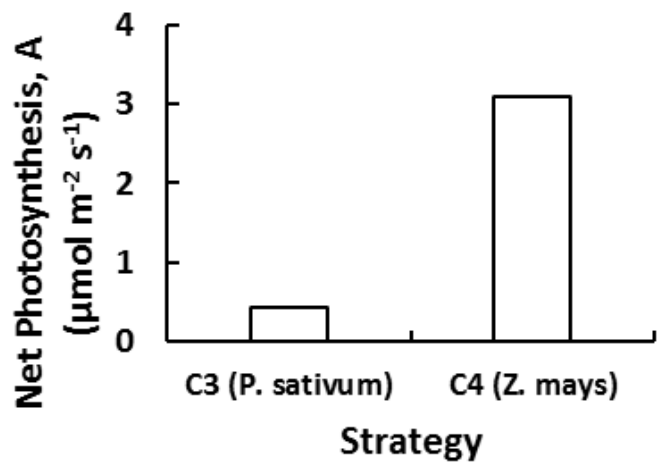

C.

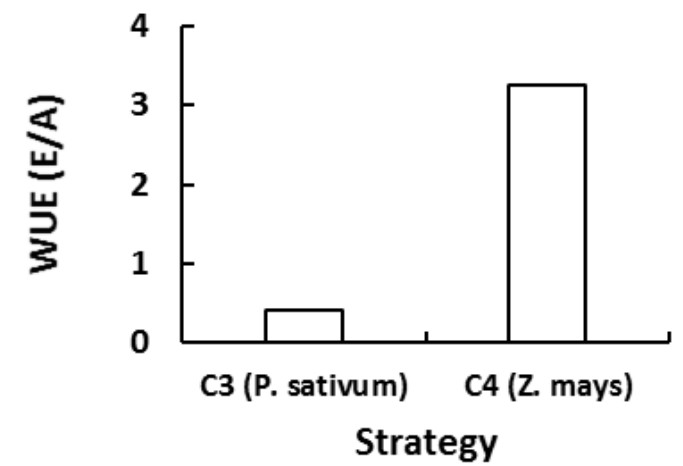

b.

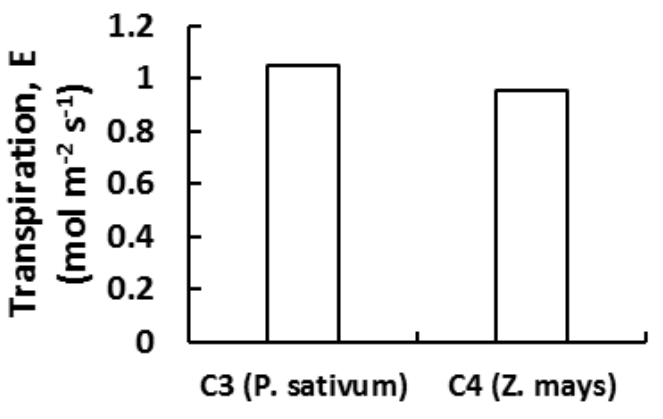

Strategy

d.

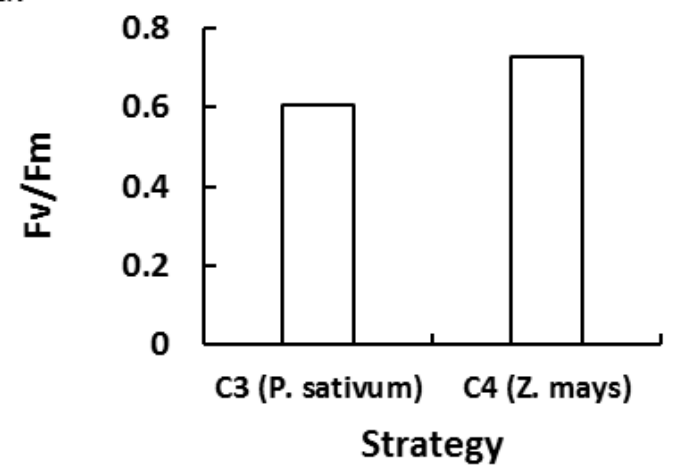

Figure 4. Effect of carbon strategy on photosynthesis (a), transpiration (b), water use efficiency (WUE) (c), and photoinhibition (Fv/Fm) (d). 
a.

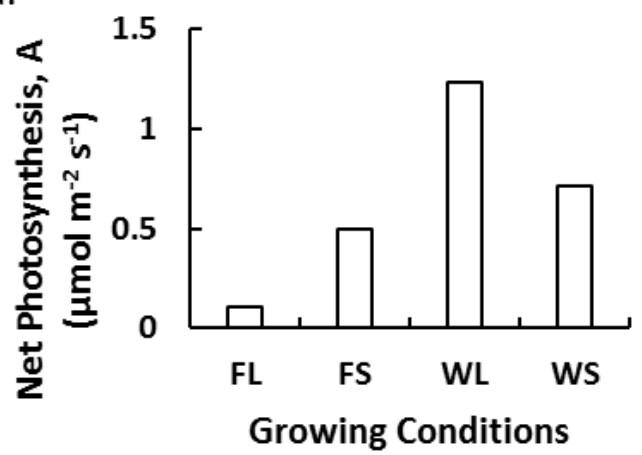

c.

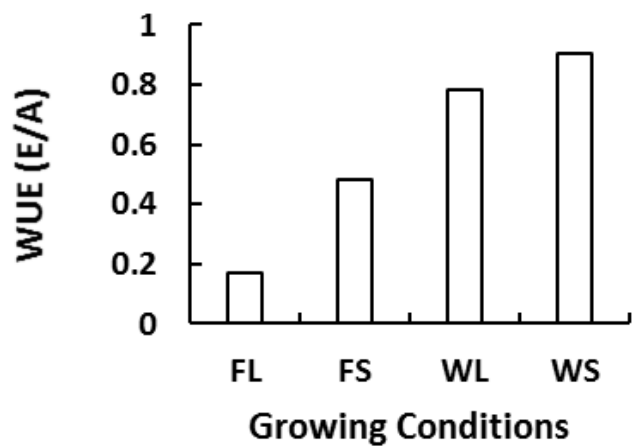

b.

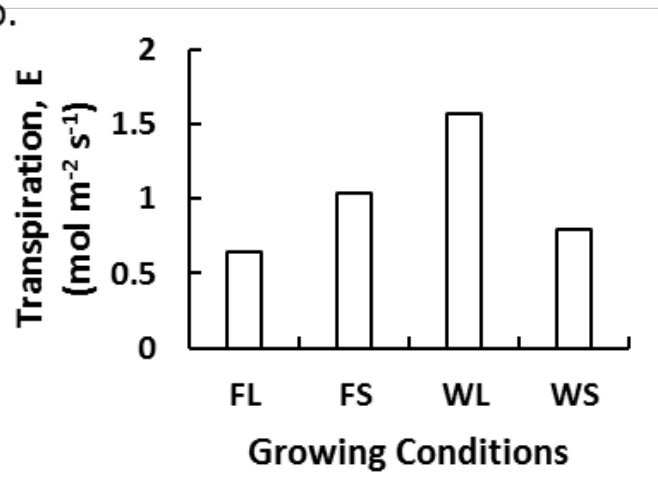

d.

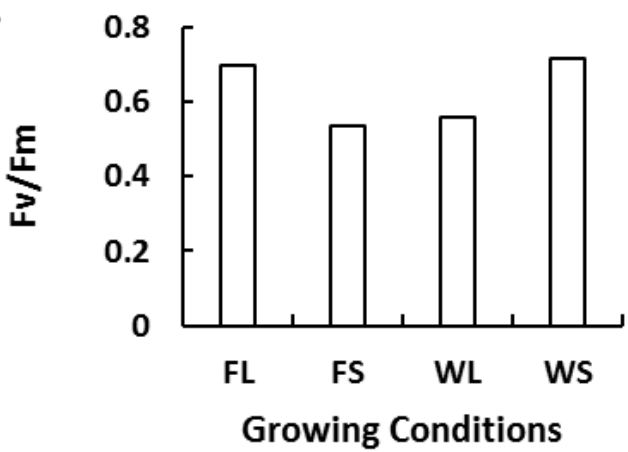

Figure 5. Effect of light and nutrients on photosynthesis (a), transpiration (b), water use efficiency (WUE) (c), and photoinhibition (Fv/Fm) (d) in $E$. angustifolium. $\mathrm{FL}=$ fertilized, light; FS = fertilized, shade; $\mathrm{WL}=$ water, light; $\mathrm{WS}=$ water, shade.

a.

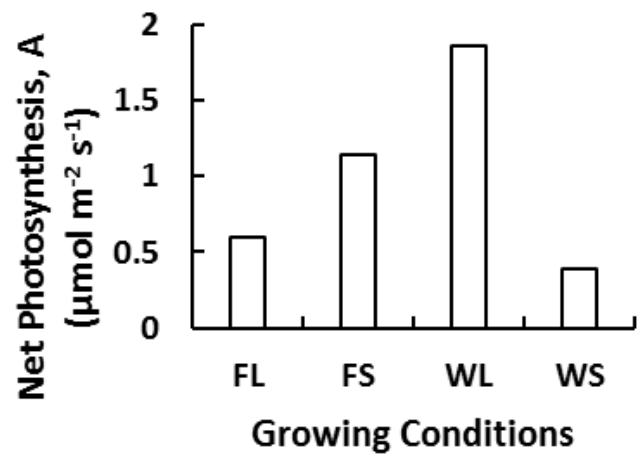

c.

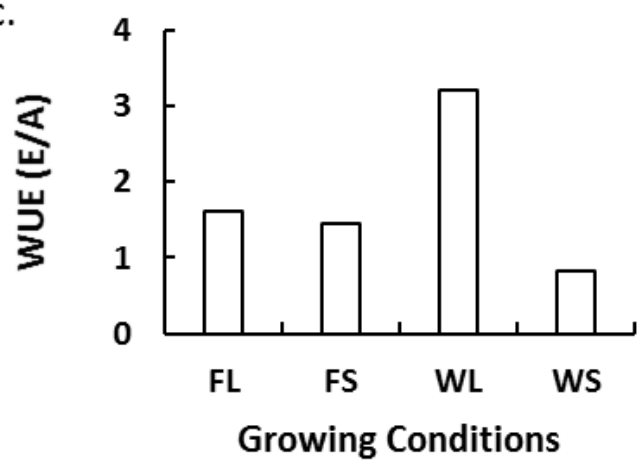

b.

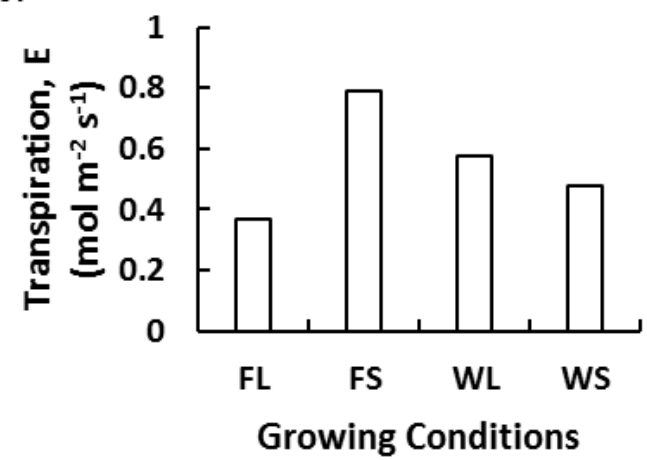

d.

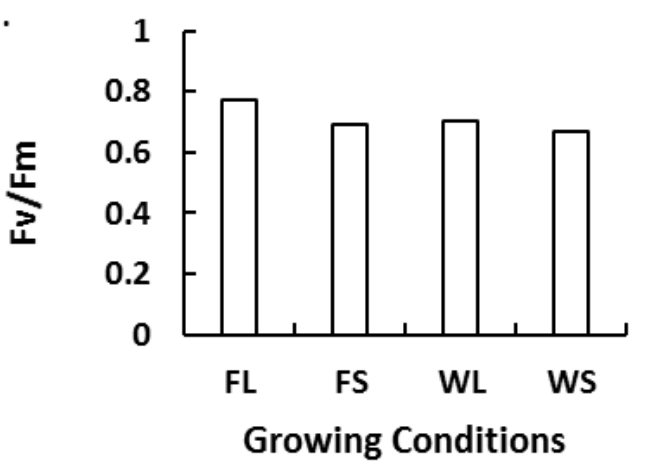

Figure 6. Effect of light and nutrients on photosynthesis (a), transpiration (b), water use efficiency (WUE) (c), and photoinhibition (Fv/Fm) (d) in $G$. hederacea. $\mathrm{FL}=$ fertilized, light; FS = fertilized, shade; WL = water, light; WS = water, shade. 


\subsection{Photosynthesis and Photoinhibition}

PAM 2000 and Licor 6400 devices were used to detect the functional responses and strategies of different plant species under various environment conditions and stresses. The Licor 6400 device was used to measure photosynthetic rate, transpiration rate, photosynthetically active radiation (PAR) and $\mathrm{CO}_{2}$ level. The PAM 2000 device, a portable chlorophyll fluorometer, was used to measure photoinhibition.

\section{Results}

The first experiment involving the intensity of light shows that at mid-range intensities the rate of photosynthesis begins to climb, but once the intensity exceeds a certain amount, the ability of a plant to photosynthesize effectively slows. At negligible light levels plants undergo net photorespiration (PAR intensity: $20 \mu \mathrm{mol}$ photon ${ }^{-1} \mathrm{~s}^{-1}$; black circles) (Fig. 1), which includes dark respiration. Net photosynthesis rapidly increases to positive values when PAR intensity is increased to $324 \mu \mathrm{mol}$ photon ${ }^{-1} \mathrm{~s}^{-1}$ (grey circles), but at the higher PAR intensity of $1024 \mu \mathrm{mol}$ photon ${ }^{-1} \mathrm{~s}^{-1}$ (white circles) photosynthesis begins to plateau.

Photosynthesis, transpiration levels, water use efficiency and $\mathrm{Fv} / \mathrm{Fm}$ were measured for plants grown under different water regimes, varying life stages, carbon strategies and variable light and nutrient conditions. Data was compiled and means of four replicate groups $(n=4)$ were used. Error bars were not included in figures since the low sample size resulted in high variability and large errors that dwarfed the actual results. If sample size was larger meaningful statistical analyses could be performed, but in this case only superficial comparisons could be made.

In the first of these experiments, it was found that in $V$. vitis-idaea, net photosynthesis occurred under moist conditions, but the plant underwent photorespiration in dry and cold conditions (Fig. 2a). Transpiration levels were high in moist and cold conditions and in dry conditions were approximately half as intense (Fig. 2b). Water use efficiency, calculated by dividing photosynthesis by transpiration followed the same pattern as the photosynthesis results (Fig. 2c). The Fv/Fm data is how well the plant recovers from photoinhibition and scores near 0.8 signify excellent recovery. The moist and cold conditioned plants responded well to the photoinhibition test, while dry condition plants did not perform as well (Fig. 2d).

In C. coggygria, senescence appears to drastically impact many of the plants functional features shown by the high degree of photorespiration, low water use efficiency and extremely low Fv/Fm (Fig. 3 a, c, d). However, the senescent leaf has highly similar transpiration rates as the healthy green leaf (Fig. 3b).

Comparing carbon strategies, it was evident that the $\mathrm{C} 4(Z$. mays) strategy is well suited to high intensity light conditions with its comparably higher net photosynthesis, water use efficiency and $\mathrm{Fv} / \mathrm{Fm}$ (Fig. 4a, c, d). Although transpiration was lower in the $\mathrm{C} 4$ sample, it was expected to be more noticeably lower than in C3 (P. sativum) plants (Fig. 4b).

$E$. angustifolium as a relatively shade intolerant species it was expected that the samples grown in low light and no fertilizer would result in the lowest performance. It was seen that the fertilized samples had the lowest photosynthetic rates, low transpiration and water use efficiency (Fig. 5a, b, c). The high fertilizer in light sample performed poorest overall, except was able to recover well from photoinhibition (Fig. 5d). Fertilized shade plants did marginally better than fertilized light plants, but they did not recover as well from photoinhibition (Fig 5). Water light plants had high photosynthetic rates, transpiration water use efficiency, but low Fv/Fm (Fig. 5). Finally, the water shade plants had relatively moderate levels of photosynthesis, low transpiration, thus higher water use efficiency and high Fv/Fm (Fig. 5). These results support that the plants grown without fertilizer and in shade had better overall performance in comparison to the other treatments.

$G$. hederaceae by contrast is a relatively shade tolerant species, so for these treatments it was expected that the fertilized samples grown in low light would perform the best. Unfertilized light samples had the highest photosynthetic rates, moderate transpiration, and the best water use efficiency, with comparable Fv/Fm values (Fig. 6). The rest of the samples had good Fv/Fm values, but the fertilized light samples have marginally better recovery abilities (Fig. 6d). Fertilized light samples had low net photosynthesis, low transpiration, therefore low water use efficiency like fertilized shade plants, which had the highest levels of transpiration, but more net photosynthesis than fertilized light plants. Unfertilized shade plants had the lowest net photosynthesis and moderate transpiration resulting in the lowest water use efficiency (Fig 6). Overall, the unfertilized light plants seem to perform the best relative to the other treatments.

\section{Discussion}

The results of the first experiment testing increasing PAR intensity followed the expected trend. At low light intensity photorespiration dominates because there is not enough energy to fix sufficient carbon for the Calvin cycle resulting in no net photosynthesis. As light intensity increases so does photosynthesis and at the highest intensity photoinhibition begins to slow the plant's photosynthetic capabilities. In this experiment the intensity was not great enough to photo-oxidize the plant and so photosynthetic rates continued to increase, albeit more slowly.

In moisture and cold experiments with $V$. vitis-idaea we expected positive net photosynthesis in moist conditions and that in dry and cold conditions there would be little to no net photosynthesis. In dry conditions the lack of water reduces photosynthetic rate, and in cold conditions plants become 
more sensitive to photoinhibition [4]. Although this may lead to limitations it was seen that cold grown plants maintained relatively high $\mathrm{Fv} / \mathrm{Fm}$ values so photoinhibition may not be the only factor leading to high photorespiration. Cold stress has been found to reduce net photosynthesis in chilled crop plants via inhibition of reducing components of the photosynthetic pathway like iron-sulfur clusters on photosystem I, impacting the reduction pathway more than the oxidizing pathway [5]. Lower transpiration rates in dry conditions were expected as lower soil water content means a reduction in water potential and less transfer of water into root systems.

In senescent leaves transpiration rate remained comparable to the green leaf. In previous studies, it was found that senescence reduced net photosynthesis and water use efficiency as was expected because of the reduction in photosynthetic pigments (change to yellow) [6]. The same experiment found that transpiration also decreased as leaves senesced. It is not entirely abnormal for senescing leaves to transpire if residual water remains in the leaf.

Z. mays as a $\mathrm{C} 4$ strategist had higher net photosynthesis, water use efficiency and $\mathrm{Fv} / \mathrm{Fm}$ rates, but it didn't have noticeably lower transpiration rates. The advantages of $\mathrm{C} 4$ photosynthesis over $\mathrm{C} 3$ photosynthesis have been shown to be maximal under conditions of high light intensities, high temperatures and limited water supply [7]. Since plants were grown under similar conditions there were not large differences in the transpiration and $\mathrm{Fv} / \mathrm{Fm}$ results, but if grown in higher light intensity transpiration would be expected to be higher in $\mathrm{C} 3$ plants.

The results with shade intolerant species E. angustifolium were unexpected, because the best results came from the plants that had been grown without fertilizer and in shade even though the net photosynthesis was best in water and light conditions. Another explanation for low net photosynthesis was that the greenhouse light intensities were not very strong, only about $10 \%$ the intensity of outdoor sunlight, resulting in poor photosynthetic performance (Personal communication, Kari Taulavuori). When measuring the specimens of $E$. angustifolium it was noticeable that they had suffered from drought or toxicity from over-fertilization affecting the results. It was also discovered that the experimental growth period was abnormally long. In nature these species grow, flower and senesce within 1.5 months whereas the individuals grown for this study were kept for 3.5 months. G. hederacea is a shade tolerant species and was thought to perform best in fertilized conditions in shade. In the end the plants grown in unfertilized and light conditions performed best. This is because although it is a shade tolerant plant it can also grow effectively in full light, and is well suited to both environments [8].

\section{Conclusions}

Future work may explore transpiration in senescing leaves and perhaps look at a variety of species of plant to compare how different leaf morphologies impact this leaf function. For fertilizer and light studies perhaps a more shade dependent species than G. hederacea could be tested. Also, levels of the fertilization treatment should be re-evaluated to avoid over-fertilization of treatments. Additionally, larger sample sizes should be used in order to obtain a larger data set to perform statistical analyses to determine the actual degree to which the tested factors impact plants' photosynthetic abilities.

\section{REFERENCES}

[1] S. G. Pallardy. Photosynthesis. Pages 107-167 in S. G. Pallardy, editor. Physiology of Woody Plants. Academic Press, Elsevier, Inc. Burlington, Massachusetts, USA, 2008.

[2] H. Lambers, F. S. Chapin III, T. L. Pons. Plant Physiological Ecology. Springer Science Business Media. 1998.

[3] S. W. Hogewoning, G. Trouborst, H. Marjaars, H. Poorter, W. Leperen, J. Harbinson. Blue light dose-reponses of leaf photosynthesis, morphology and chemical composition of Cucumis sativus grown under different combinations of red and blue light. Journal of Experimental Botany. 61, 3107-3117, 2010.

[4] K. Taulavuori, E. Bauer, E. Taulavuori. Overwintering stress of Vaccinium vitis-idaea in the absence of snow cover. Environmental and Experimental Botany. 72, 397-403, 2011.

[5] P. Thakur, S. Kumar, J. A. Maik, J. D. Berger, H. Nayyar. Cold stress effects on reproductive development in grain crops: An overview. Environmental and Experimental Botany. 67, 429-443, 2010.

[6] R. G. Woodward, H. M. Rawson. Photosynthesis and Transpiration in Dicotyledonous Plants. II. Expanding and Senescing Leaves of Soybean. Australian Journal of Plant Physiology. 3, 257-267, 1976.

[7] J. Ehleringer, O. Björkman. Quantum Yields for $\mathrm{CO}_{2}$ Uptake in $\mathrm{C}_{3}$ and $\mathrm{C}_{4}$ Plants. Plant Physiology. 59, 86-90, 1977.

[8] J. Q. Wang, D. P. Yang, N. Zhu, D. Yung, J. W. Mang. Study on the shade-tolerance of ability of Glechoma hederacea. Nature Environment and Pollution Technology. 13, 613-618, 2014. 